\section{Peer Leader Reflections on Promoting Discussion in Peer Group-Learning Sessions: Reflective and Practiced Advice through Collaborative Annual Peer-Advice Books}

\author{
Gabriela Szteinberg, ${ }^{\dagger}$ Michelle D. Repice, ${ }^{\ddagger}$ Claudia Hendrick, ${ }^{\S}$ Stephen Meyerink, ${ }^{\S}$ \\ and Regina F. Frey ${ }^{\dagger \$ \| *}$ \\ ${ }^{\dagger}$ Department of Chemistry, ${ }^{\ddagger}$ Career Center, and \$ Center for Integrative Research on Cognition, \\ Learning, and Education (CIRCLE), Washington University in St. Louis, St. Louis, MO 63130
}

\begin{abstract}
As research has shown, collaborative peer learning is effective for improving student learning. Peer-led team learning (PLTL) is one well-known collaborative-group approach in which groups are facilitated by trained undergraduate peer leaders. This paper contributes to the literature on peer-leader training by examining how peer leaders for a large introductory science course translate their training into practice during their sessions. By conducting qualitative analysis on annual advice books written by emergent peer leaders, we examined the practiced advice and strategies of these peer leaders as they facilitate PLTL groups in a university-level general chemistry course. These advice books are passed on to future peer instructors, creating a community of practice between new and more experienced peer leaders. From the analysis, we discovered that peer leaders focus on developing robust student-student discussion during complex problem solving by 1) creating a community-oriented social and intellectual environment, 2) adapting their tactics and the collaborative-learning strategies to balance different personalities and promote equal participation among all students, and 3) modifying collaborative group approaches when facilitating their sessions. Also, in their correspondence across cohorts, peer leaders provided near-peer support to one another. These annual books disseminate practiced advice between peer-leader generations and are used during new peer-leader training.
\end{abstract}

\section{INTRODUCTION}

As prior research has shown, collaborative peer learning is an effective approach for improving student learning (Eberlein et al., 2008; Arendale, 2015; Van Dusen et al., 2015; Wilson and Varma-Nelson, 2016; Sellami et al., 2017). In biology, both peer-led team learning (PLTL) and learning assistant (LA) programs are well-known collaborative group approaches based on social constructivism (Vygotsky, 1980; Bodner et al., 2001; Eberlein et al., 2008; Otero et al., 2010) in which students build their knowledge of concepts by discussing, critiquing, and sharing ideas in a social environment. In both PLTL and LA programs, the collaborative groups are facilitated by trained undergraduate peer leaders (Gosser and Roth, 1998; Gafney and Varma-Nelson, 2008; Wilson and Varma-Nelson, 2016; Otero et al., 2010; Learning Assistant Alliance, 2011). This paper presents qualitative results from reflections by first-time peer leaders via their viewpoint on how they encourage and promote effective student-student group discussions in their peer groups in a PLTL program for a university-level general chemistry course. Therefore, this study may provide practical insight to others who are learning to facilitate student-student discussions during problem solving in collaborative groups in introductory science courses.
Jennifer Knight, Monitoring Editor Submitted May 20, 2019; Revised Oct 23, 2019; Accepted Oct 24, 2019

CBE Life Sci Educ March 1, 2020 18:ar2

DOI:10.1187/cbe.19-05-0091

"Present address: Department of Chemistry, University of Utah, Salt Lake City, UT 84112. *Address correspondence to: Regina F. Frey (gfrey@wustl.edu).

(c) 2020 G. Szteinberg et al. CBE-Life Sciences Education @ 2020 The American Society for Cell Biology. This article is distributed by The American Society for Cell Biology under license from the author(s). It is available to the public under an Attribution-Noncommercial-Share Alike 3.0 Unported Creative Commons License (http://creativecommons.org/licenses/ by-nc-sa/3.0)

"ASCB $®$ " and "The American Society for Cell Biology $\circledR^{\prime \prime}$ are registered trademarks of The American Society for Cell Biology. 
Peer instructors for large, introductory science, technology, engineering, and mathematics (STEM) courses support students who are facing the challenges of learning the process of complex problem solving. Our study explored the reflective and practiced advice that emergent chemistry peer leaders selected to pass on to future chemistry PLTL facilitators through a collaborative annual book written at the end of a one-semester STEM-focused peer-leader training course. The advice from the books consists of community-creating and facilitation strategies to promote student-student discourse that fosters collaborative knowledge and skill building during problem-solving group work, especially in introductory STEM courses, and therefore could be transferable to peer instructors in other STEM departments, because the advice is not content specific. Our peer leaders also create and share in multiple communities of practice (CoPs). Hence, this study may provide new insights to biology educator researchers and biology educators who train peer instructors assisting collaborative groups in their courses.

\section{Benefits of Collaborative Peer Instruction}

In STEM, most peer-learning research focuses on performance outcomes to show that collaborative learning is one way for students to engage more deeply with content and to practice using disciplinary vocabulary, skills, and knowledge (Peteroy-Kelley, 2007; Preszler, 2009; Batz et al., 2015; Knight et al., 2015; Repice et al., 2016; Frey et al., 2018). There are many performance studies in introductory biology using PLTL (Drane et al., 2005; Preszler, 2009; Snyder and Wiles, 2015; Carlson et al., 2016; Kudish et al., 2016) and LA (Batz et al., 2015; Talbot et al., 2015; Van Dusen et al., 2015; Sellami et al., 2017) models, as well as in many other STEM disciplines, showing the robustness of both approaches (Lewis, 2011; Talbot et al., 2015; Van Dusen et al., 2015; Wilson and Varma-Nelson, 2016).

Participating in collaborative scientific discourse encourages learners to verbally explain their evolving ideas (Sawyer, 2005; Andriessen, 2006; Krajcik and Blumenfeld, 2006), and recent studies on student discourse in small-group science settings have shown that student talk is important to student learning in these settings (Peteroy-Kelley, 2007; Becker et al., 2013; Kulatunga et al., 2013; Young and Talanquer, 2013; Knight et al., 2015). Problem solving in these peer environments engages students in habits and skills similar to ones practicing scientists use, and participating in peer scientific discourse helps students to better define their understanding of concepts (Lemke, 1990; Sawyer, 2005; Krajcik and Blumenfeld, 2006; Repice et al., 2016). Using discourse analysis, several studies have found that the type of questions a peer leader asks and the peer leader's interaction style markedly affects the amount and depth of student discourse that occurs in these small-group settings using both PLTL and LA approaches (Brown et al., 2010; Sawyer et al., 2013a,b; Knight et al., 2015). This finding that peer leaders play a key role in affecting student-student discourse is also seen in $\mathrm{K}-12$ studies about teachers' affecting student discussion (e.g., Carlsen, 1993; Hanrahan, 2005). Hence, one key component for effective peer learning is that facilitation needs to encourage robust student-student discussion of concepts during problem solving (Sellami et al., 2017; Eren-Sisman et al., 2018), and this is a key responsibility of the peer leader in the PLTL and LA models.
Both models require training of peer leaders to become skilled facilitators, especially in promoting student-student discussions (Gosser and Roth, 1998; Gafney and Varma-Nelson, 2008; Wilson and Varma-Nelson, 2016; Otero et al., 2010; Chan and Bauer, 2015; Sellami et al., 2017). Several approaches to training exist. For example, Gosser et al. (1996) described training peer leaders via frequent meetings with faculty, in which peer leaders review workshop materials and discuss these materials with their peers. Other institutions developed semester-long training courses (Tien et al., 2004; Hockings et al., 2008; Otero et al., 2010; Chan and Bauer, 2015; Sellami et al., 2017), most of which contain the following components: 1) introduction to appropriate education-research literature; 2) discussion of how to apply this research to their sessions; and 3) self-reflection of each session followed by feedback. These courses also help to create CoPs among peer leaders and between peer leaders and faculty/staff involved in the program. There are limited studies focusing on how peer leaders translate their training into practice and how they help advise one another through CoPs. Recent studies, using interviews or reflective journals, have found that peer leaders go through a developmental process in becoming peer leaders (Micari et al., 2006; Johnson et al., 2015; Glover et al., 2018). In this study, by analyzing annual advice books, we collected strategies and insights that chemistry peer leaders self-report using in their session to "create and sustain a positive supportive learning environment" (Chan and Bauer, 2015, p. 342) that promotes student-student discourse during problem solving, as seen in Sawyer et al. (2013b) and Knight et al. (2015). Written at the end of the first peer-leading semester, these books contain the reflective and practical advice emergent peer leaders believe are most important to successful peer leading for a large introductory STEM course. We seek to add to the current documentation on peer-leader training by examining how emergent peer leaders at one institution translate their training into practice in their PLTL sessions.

\section{Theoretical Framework}

Peer leaders, experienced and new, advise and coach one another as CoPs and through cognitive apprenticeship (Collins et al., 1988; Dennen and Burner, 2008), both of which stem from Vygotsky's sociocultural development of cognition (Vygotsky, 1980), and help new peer leaders go through their zone of proximal development (ZPD; Vygotsky, 1980) as they are developing as peer leaders.

CoPs are groups of people having a common domain of interest (in our study, peer leading in introductory STEM courses) who engage collectively in joint activities and discussions sharing information and supporting one another toward improving their shared practice (Wenger, 1997). The interconnectivity of these elements forming a CoP comes from situated learning, which states learning is embedded within activities of the learner (Brown et al., 1989; Lave and Wenger, 1991), and it is these social activities that provide the correct context for learning to take place. Situated learning derives from social-learning theory (Bandura, 1977), which states that people learn from observing and interacting with others. These ideas comprise an essential component of our peerleader training.

We visualize our PLTL program as having a multilayered set of CoPs; see Figure 1. The smallest CoP is the individual PLTL 


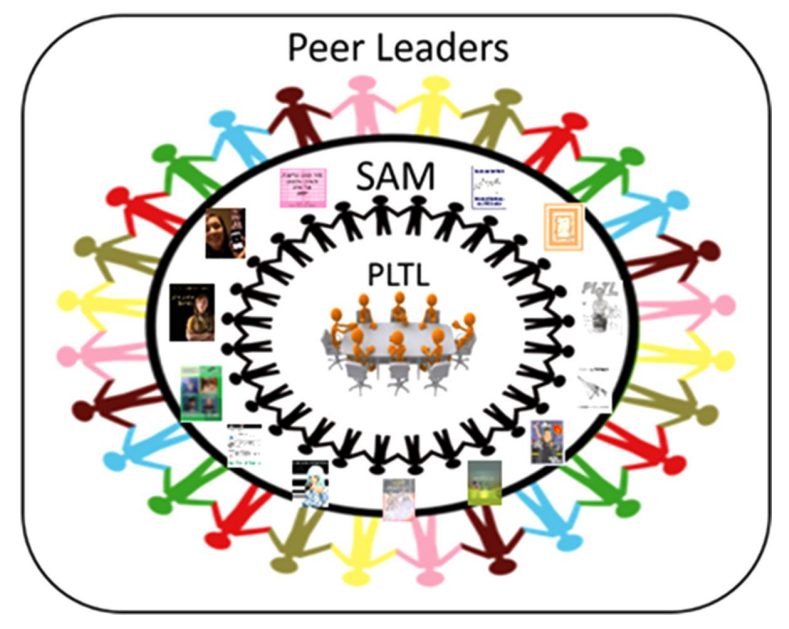

FIGURE 1. Schematic of the multilayered CoP experience. At the center is the individual PLTL group with students and their peer leader. The next layer is the SAM cohort. The outer layer represents all of the trained peer leaders, who are connected to the SAM cohort via the SAM books.

group, which comprises a peer leader and the students in his or her PLTL group. The next CoP consists of new peer leaders who train together in the SAM course (described later) during their first semester of peer leading and support one another during this new experience. The largest CoP that involves just peer leaders (we acknowledge that the peer leaders and the instructors form another CoP) comprises all past and current peer leaders who have contributed to strategies used in PLTL sessions via the practiced advice and insights passed down from previous SAM students in an annual collaborative book (described later) and from their own experiences as peer leaders in their sessions. Thus a key link between these CoPs is the advice written in these SAM books.

Cognitive apprenticeship, as described by Collins et al. (1988), occurs in our PLTL CoPs. That is, new peer leaders become members of the larger chemistry peer-leader CoP, and through this larger CoP, inherit and engage in the culture of observing, having guided practice, and reflecting on the skilled practice needed to lead a general chemistry PLTL session, primarily from the advice books but also from the weekly PAM training course (described in PLTL section). From this apprenticeship training and simultaneous reflective practice, peer leaders take part in situated cognition (Brown et al., 1989). All peer leaders since the program's conception have written an advice book for the new chemistry peer leaders the following year. Over time, this practiced advice has been modified, added to, and elaborated on as peer leaders discover what works best for them and their students. Through the analysis of these books, we have access to practiced advice and insights passed down and added to from one emergent peer-leader CoP to another.

\section{Research Questions}

We examined the reflective and practice-based experiences of emergent chemistry peer leaders as they navigate their first semester of leading. The following questions guided this investigation:
- What do peer leaders report doing to create and maintain a conducive environment for effective problem-solving discussions in collaborative groups?

- What do peer leaders report doing to manage group dynamics such that all members of the PLTL group participate, including managing different student personalities and maintaining healthy group dynamics?

- What do peer leaders report doing to effectively facilitate groups to encourage group learning and collaborative knowledge building across different types of problems, skills, and content?

\section{PLTL Program}

The PLTL program at our institution is implemented in the general chemistry series, the calculus sequence, and the introductory physics series, using similar discipline-based training courses, PLTL philosophy, logistics, and hiring practices. Our PLTL groups consist of 10 students facilitated by a trained undergraduate peer leader. Students enroll in the program; however, once students enroll, attendance is mandatory, and they sign a contract agreeing to certain responsibilities. Frey et al. (2018) contains details about our program.

Students receiving an "A" course grade in General Chemistry 1 and participating in one of the three PLTL programs are invited in the Spring to apply for $\sim 30$ new peer leader positions, joining returning peer leaders for a total of 70 leaders for chemistry. These peer leaders are trained via two courses, which are discipline specific: 1) every semester, the peer leaders take Practical Applications of Academic Mentoring (PAM), in which the peer leaders prepare for the chemistry content of each week's PLTL session by working through the problems in collaborative groups, as well as observing one another in weekly PLTL sessions; and 2) the first-semester peer leaders take Seminar in Academic Mentoring (SAM), in which peer leaders learn how to effectively facilitate a chemistry PLTL group. The PLTL director and project coordinator (both PhDs in chemistry and members of the general chemistry instructor team) teach these courses and observe the peer leaders each semester to give structured feedback for the peer leaders to continually refine their facilitation skills.

\section{SAM}

The SAM course topics have remained fairly constant over the years, as these topics cover education research literature and evidence-based best practices that pertain to the philosophy and implementation of general collaborative-learning methods in STEM and PLTL specifically. As new studies appear, the course material is appropriately updated and modified; for example, we are currently including more material on inclusion, diversity, and equity. The main topics and an example syllabus are in the Supplemental Material. The evidence-based research background, the best practices, and common issues and strategies for each topic are discussed based on 1) instructors' expertise and experience about collaborative learning and their knowledge and experience with issues students have when learning complex problem solving; 2) literature on educational research and cognitive and social psychology and evidence-based practices for PLTL; 3) the annual SAM book essays; and 4) current peers in SAM. For example, one session discusses studies on the effects of adopting a growth mindset 
and how peer leaders can help students foster a growth mindset to handle the challenges they encounter in learning general chemistry and being in a large introductory science course. Another session concerns learning and memory and studies showing which study techniques are more useful in learning chemistry and gaining complex problem-solving skills. For example, self-explanation of or explaining to others concepts used in problem solving helps learners modify or clarify their understanding of relevant subject matter (Dunlosky et al., 2013).

Selected SAM Assignments. The SAM peer leaders read the SAM book written by the prior year's SAM cohort and write reflection papers for each section of the book. In the reflections, they must cite at least three essays from that section and provide specific examples of how the essays or recent topics discussed in SAM relate to their own experiences with their chemistry PLTL groups. In these reflective essays, we have current peer leaders' self-reports on how they are translating the advice and insights from the SAM books into their own sessions.

The SAM peer leaders also post to an online course discussion board an issue or success that occurred in a recent session, with different peer leaders responding. From this assignment, we have observed an informal learning community outside of the SAM session forming via this discussion board (i.e., another CoP component), and this is another source of self-reported reflections and responses on how peer leaders are translating their training into practice.

SAM Books. As a final project, the SAM peer leaders write two-page essays for the next generation of new chemistry peer leaders, which they combine into an advice book. The SAM peer leaders choose the book theme, which is typically current life topics that the peer leaders relate to the PLTL philosophy; for example, Beyoncé, The Hunger Games, and memes. These books may be found online at https://circle .wustl.edu/collaborations/peer-led-team-learning/peer -leader-training-books.

Each essay contains practiced advice on how to promote effective student-student group discussions during problem-solving activities in a chemistry PLTL session, as well as words of encouragement and compassion for forgiving themselves for making inevitable mistakes. During the SAM class, the peer leaders work in small groups by book section to decide what they will focus on in their personal essays and to ensure that the information is corroborated by others and diversified within each specific book section. Within these small groups, the peer leaders discuss advice and insights each believes is important in facilitating an effective science PLTL group, which results in peer corroboration and peer refinement of the set of collective advice and insights. The goal is to endorse and diversify the amount and type of advice being given.

The essay prompt given to the SAM peer leaders (in the syllabus) is

"As a group, you will discuss what you have learned this semester as peer leaders or mentors, and create a collection of essays about what you have learned. The group will pick topics to cluster the essays around, and will pick a title. The collec- tion will be bound and given to next year's new PLTL peer leaders and mentors.

"Grading of group project includes: Essay Title; Group dynamics during discussion; and Essays, which are graded according to grading criteria for papers (e.g., use specific examples from your group, develop ideas through supporting detail and evidence, clearly written)."

This prompt gives no guidance from the SAM instructors on the actual essay content, and the grading is not dependent upon specific solutions or advice being present in the essays. Hence, the peer leaders are in control of what they believe is important to pass on to future peer-leader cohorts. The books are focused on practiced advice, not course content, and therefore can be used by other STEM peer-leading programs that train peer leaders, especially for large introductory STEM courses. For example, at our institution, for their first year of PLTL implementation, the Physics Department used the chemistry SAM book, as did the supplemental-support programs in our Learning Center.

\section{METHODS}

Our setting for this study is a medium-sized, selective research university in the U.S. Midwest. The data consist of essays written by emergent peer leaders at the ends of their first semesters of leading general chemistry PLTL sessions. This study includes 13 books (2003-2015), each comprising 30 essays. We employed a phenomenology lens (Patton, 2002) and the constant comparative method (Glaser and Strauss, 1967) to identify emergent themes and categories of practiced advice in facilitating peer learning, based on the common lived experiences of peer leaders as they navigated their first semesters of leading groups. We developed our research questions from key ideas identified in the 13 books and established a coding scheme using all books (413 essays total). To answer our research questions, we used essays from the last 3 years in the study (2013-2015; 92 essays), which provide the most recent practiced advice and insights from our emergent peer leaders. Table 1 outlines the discourse analysis process, which includes the study design, code development, and analysis.

The researchers collaboratively interpreted common ideas and threads, selected all entries that helped to answer the research questions, and meaningfully grouped the data (Bogdan and Biklen, 2003; Denzin and Lincoln, 2003; Yin, 2010). The researchers participating in coding encountered the data from different perspectives: 1) G.S., as a science-education specialist and instructor of the chemistry SAM course; 2) M.R., as an experienced researcher in qualitative analysis; 3) S.M., as a master's student in humanities; and 4) C.H., as an upper-level undergraduate student who experienced General Chemistry PLTL.

Using our research questions, we performed content analysis of the essay text through a three-phase process: 1) establishing primary themes based on the research questions using all 13 books (2003-2015); 2) iteratively coding to identify categories and subcategories using the 2013-2015 books and finalizing interrater reliability and the coding scheme using random samples of excerpts from all 13 books (2003-2015); and 3) using the final coding scheme to code all of the excerpts in 
TABLE 1. Discourse analysis process

\begin{tabular}{|c|c|c|c|}
\hline Study design & Phase 1 (themes) & Phase 2 (categories) & Phase 3 (analysis) \\
\hline $\begin{array}{l}\text { Identified emergent themes and } \\
\text { categories based on all } 13 \text { books } \\
\text { (2003-2015) } \\
\text { From key ideas in all } 13 \text { books, } \\
\text { developed the three research } \\
\text { questions } \\
\text { - Used most recent books } \\
\text { (2013-2015) to answer research } \\
\text { questions }\end{array}$ & $\begin{array}{l}\text { Established primary themes } \\
\text { based on research questions } \\
\text { using all } 13 \text { books (2003- } \\
\text { 2015) } \\
\text { - Finalized excerpts in all } 13 \\
\text { books that addressed the } \\
\text { three research questions }\end{array}$ & 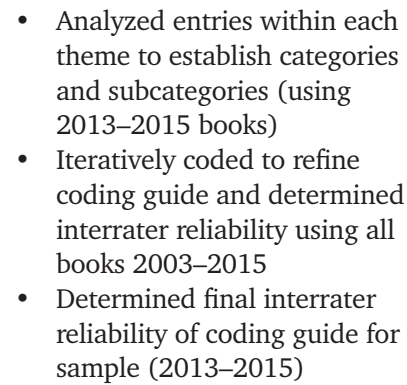 & $\begin{array}{l}\text { - Using the final coding } \\
\text { scheme, coded all excerpts } \\
\text { with themes, categories, and } \\
\text { subcategories for books } \\
2013-2015 \\
\text { - Results and discussion basec } \\
\text { on books 2013-2015 }\end{array}$ \\
\hline
\end{tabular}

books from 2013-2015 to obtain the results discussed in this paper (see Table 1).

\section{Phase 1}

Using all 13 books, M.R. and S.M. selected all excerpts that contained a suggestion or strategy for handling the situation described in any of our three research questions and coded these entries for further analysis. Table 2 shows the themes, categories, and subcategories and corresponding research questions. Entries that described a peer leader's strategy for helping to establish and maintain a conducive environment for group problem solving were coded for the Environment theme (E). We coded statements that commented on strategies to ensure positive group dynamics among peer-group members and approaches that encourage equal participation as the Group Dynamics theme (GD). Entries that included details about processes peer leaders used to support their groups in moving collaboratively through the problems without providing answers were coded for the Facilitation theme (F). Portions of essays containing no discernible advice regarding concrete strategies to address the specific inquiries described in our research questions were not coded. Table 3 shows the number of entries in each category.

\section{Phase 2}

G.S., M.R., and S.M. iteratively analyzed the entries within each theme from the 2013-2015 books to establish meaningful categories and subcategories of peer leader behaviors, attitudes, and actions. After determining these initial categories and subcategories, G.S., M.R., and S.M. independently coded a random sample of 200 excerpts for each theme from all 13 books (600 total entries), using the categorization scheme; this sample consisted of $32 \%$ of all entries. Through group discussion, a final categorization scheme that incorporated all 600 entries in this sample into categories and subcategories was developed, and a coding guide with definitions and data examples for each category and subcategory was created. Once the coding guide was established, G.S. and M.R. tested the guide on a new random sample of 50 excerpts from each theme (150 total excerpts) from books before 2013 ( $12 \%$ of the available entries) to check for agreement. Interrater reliability was determined to be $88 \%$ for Environment, $70 \%$ for Facilitation, and $62 \%$ for Group Dynamics. For each coding disagreement, the coders discussed their reasons for coding the excerpt and quickly reached $100 \%$ agreement on the codes, and then refined the definitions of each theme, category, and subcategory to ensure clear definitions in the guide. The detailed coding guides with descriptions of each category and subcategory and example excerpts are listed in Supplemental Tables S1-S3. Finally, using the 2013-2015 books (92 essays total), G.S. and M.R. coded a new random sample (150 excerpts total), which is $23 \%$ of the available entries, with interrater reliability being $100 \%$ agreement. It is standard practice for multiple raters to examine and calibrate their coding on only a subset (10-30\%) of the total data set (Potter and Levine-Donnerstein, 1999; Krippendorff, 2004). Through the multiple-step process described, we reached theoretical saturation, which means that no new themes, categories, or subcategories emerged during the iterative coding and interrater reliability process and throughout phase 3 of the coding (Potter and Levine-Donnerstein, 1999; Lombard et al., 2005).

\section{Phase 3}

C.H. was trained on how to use the final coding scheme and then coded all excerpts from books 2013-2015 with themes, categories, and subcategories. G.S. and M.R. reviewed the work of C.H. to determine agreement, which was 100\% agreement. In the Results, we discuss the categories and subcategories of the three themes that contain the greatest number of excerpts from the 2013-2015 books.

This study has been approved by the Institutional Review Board of Washington University in St. Louis (IRB ID\#: 201306131).

\section{RESULTS}

Qualitative analysis of the SAM books revealed common themes about creative strategies and practiced advice used to encourage student-student discourse that promotes collaborative knowledge building when solving complex chemistry problems. For each broad theme (Environment, Group Dynamics, and Facilitation), we identified the most prevalent categories and subcategories. Our results reinforced the final peer-leader developmental stage presented by Johnson et al. (2015) and the long-term survey findings of Gafney and Varma-Nelson (2008), in which the peer leaders reflect on the experience with confidence and a focus on student learning. For each category, excerpts from different essays will be presented with the de-identifying three-digit code for the peer leader, the SAM book, and peer leader's sex (e.g., 564, 2013, female). The number of excerpts coded in each main theme from the 2013-2015 books are 1) Environment, 341 excerpts; 2) Group Dynamics, 
TABLE 2. Themes, categories, and subcategories in the book entries and the research question to which they correspond

\begin{tabular}{|c|c|c|}
\hline Theme & Category & Subcategory \\
\hline \multicolumn{3}{|c|}{$\begin{array}{l}\text { Research Question 1: What do peer leaders report they do to create and maintain a conducive environment for effective proble } \\
\text { discussions in collaborative groups? }\end{array}$} \\
\hline \multirow[t]{11}{*}{ Environment } & Leader Attitude & Show positivity \\
\hline & & Prepare for session \\
\hline & & Display professionalism \\
\hline & & Show confidence \\
\hline & Social Environment & Develop community \\
\hline & & Communicate with students \\
\hline & & Know your students \\
\hline & Physical Environment & Bring food \\
\hline & & Arrange space \\
\hline & Group Expectations & Introduce philosophy \\
\hline & & Establish ground rules \\
\hline
\end{tabular}

Research Question 2: What do peer leaders report they do to manage group dynamics such that all members of the PLTL group participate, including managing different student personalities and maintaining healthy group dynamics?

Group Functioning

Balancing Personalities

Promoting Equal Participation

\author{
Use strategic grouping \\ Actively monitor \\ Remind about philosophy \\ Rein in dominant students \\ Encourage quiet students \\ Strategically pair students \\ Call on students \\ Use turn-taking \\ Get students talking
}

Research Question 3: What do peer leaders report they do to effectively facilitate groups to encourage group learning and collaborative knowledge building across different types of problems, skills, and content?

Facilitation

\author{
Pacing Sessions \\ Questioning Strategically \\ Motivating Student Learning \\ Structuring Sessions
}

Promoting Group Independence

\author{
Move together \\ Take breaks \\ Move forward \\ Get back on track \\ Use wait time \\ Use redirection \\ Guide via questions \\ Encourage student explanations \\ Promote preparation \\ Provide incentives \\ Add variety \\ Vary working order \\ Review material \\ Allow student struggle \\ Encourage self-reliance
}

195 excerpts; and 3) Facilitation, 104 excerpts. Excerpts may be coded in more than one theme; therefore, these numbers do not represent uniquely coded excerpts.

TABLE 3. Number of entries in the SAM books

\begin{tabular}{lccc}
\hline Category & 2003-2012 & 2013-2015 & 2003-2015 \\
\hline Environment & 668 & 341 & 1008 \\
Group Dynamics & 277 & 195 & 473 \\
Facilitation & 286 & 104 & 390 \\
Total entries & 1231 & 640 & 1871 \\
\hline
\end{tabular}

Finding 1 (Answering Research Question 1). Setting the Stage for Effective Problem-Solving Discussions in Collaborative Peer Groups by Creating a Social and Intellectual Environment That Is Community-Oriented, Positive, and Conducive to Risk-Taking.

Peer leaders recommended several techniques, all within a peer leader's control, to create an environment that is conducive to collaborative work and enhanced student-student discussion. As seen in Figure 2, the excerpts in the Environment theme were coded into four categories: Leader Attitude (41\%), Social Environment (33\%), Physical Environment (14\%), and Group 


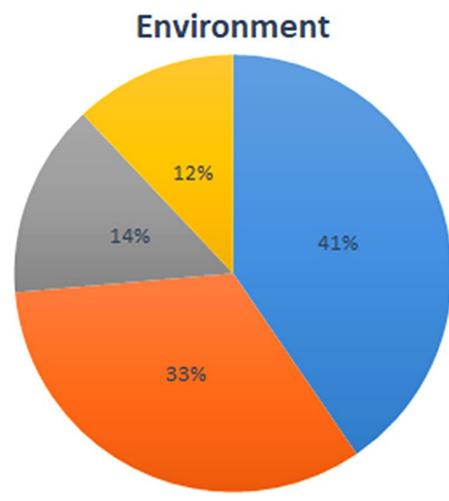

a Leader Attitude $=$ Social Environment $=$ Physical Environment $=$ Group Expectations

\section{FIGURE 2. Percent of excerpts in categories within the} Environment theme.

Expectations (12\%). Table 4 contains representative quotes for this theme. All categories and subcategories, their definitions, and example excerpts for the Environment theme are listed in Supplemental Table S1.

Leader Attitude. The most salient category in the Environment theme concerned Leader Attitude (138 excerpts, 41\%). Peer leaders described "showing positivity" to their students (56 excerpts), "being well prepared" for their sessions (44 excerpts), "acting professionally" (25 excerpts), and "showing confidence" (13 excerpts).

Peer leaders wrote about reminding their students to "stay positive" throughout the semester (see Table 4 for a quote), reassuring new peer leaders to be confident in their role (i.e., not to answer questions or confirm answers, but to help students learn in a supportive collaborative group) and providing strategies to help new peer leaders establish boundaries between students and peer leader, including tips about professionalism in this role (emphasizing preparation).

Social Environment. To establish the social environment (113 excerpts, 33\%), the peer leaders focused on "developing community" (51 excerpts), "communicating" with students (41 excerpts), and "getting to know their students" (21 excerpts).

Peer leaders stressed the importance of creating a positive and relaxed social environment where students feel comfortable with the peer leader and the other members in their groups, while meeting weekly to discuss and solve problems together. Table 4 contains representative quotes on developing community, communicating with students, and knowing your students.

Physical Environment. Peer leaders also described the importance of the physical environment (49 excerpts, 14\%) and how

TABLE 4. Representative quotes for the Environment theme

\begin{tabular}{|c|c|c|}
\hline Category & Representative subcategory & Corresponding representative quote \\
\hline Leader Attitude & Show positivity & $\begin{array}{l}\text { "Showing your students that succeeding in Gen Chem is achievable with hard work } \\
\text { will encourage them to keep trying, even if initially everything does not come } \\
\text { naturally to them." (427, 2013, Female) }\end{array}$ \\
\hline \multirow[t]{3}{*}{ Social Environment } & Develop community & $\begin{array}{l}\text { "Another thing you want to avoid is always putting the same two or three people } \\
\text { together. The PLTL program is about giving first-semester freshmen an opportunity } \\
\text { to be part of a community. The best way to encourage this is to mix the groups up, } \\
\text { so that everyone is forced to talk to everyone else. Feeling comfortable with ten } \\
\text { people rather than just one or two will really help freshmen feel part of the Wash U } \\
\text { community, while improving the group's cohesiveness." (501, 2015, Female) }\end{array}$ \\
\hline & Communicate with students & $\begin{array}{l}\text { "I told the students about how I studied for the course and how I struggled initially. } \\
\text { This makes you more relatable to the students and in the end will cause there to } \\
\text { be a stronger peer leader-mentee relationship. When you talk about the PLTL } \\
\text { philosophy, therefore, they will understand the importance of each method (small } \\
\text { group, pairs, round robin, and scribe) and will implement without any argument." } \\
(456,2014, \text { Male) }\end{array}$ \\
\hline & Know your students & $\begin{array}{l}\text { "Model the mindset-It can be very valuable to give personal experience about your } \\
\text { own struggles in classes, especially if you had to consciously improve and change } \\
\text { your approach to the class throughout the semester. This can make the concept of } \\
\text { a growth mindset much more relatable for students!" (504, 2015, Male) }\end{array}$ \\
\hline Physical Environment & Arrange space & $\begin{array}{l}\text { "During sessions, depending on the size of your room, you can make good use of the } \\
\text { space. One [peer] leader I know would have her pairs or small groups work at } \\
\text { different tables that she arranged before the start of her session which prevented } \\
\text { groups from overhearing and being distracted by the work of other groups." (500, } \\
\text { 2015, Female) }\end{array}$ \\
\hline \multirow[t]{2}{*}{ Group Expectations } & Introduce philosophy & $\begin{array}{l}\text { "As the PLTL philosophy is also introduced on the first day, this is a good time to have } \\
\text { your group make connections between the structured approaches they will be } \\
\text { using for the rest of the semester with the PLTL philosophy as a whole, and } \\
\text { reinforce the expectation that they will participate, contribute, and cooperate to } \\
\text { the group's learning as a whole." ( } 473,2014 \text {, Female })\end{array}$ \\
\hline & Establish ground rules & $\begin{array}{l}\text { "Establish some ground rules that articulate what you are there for (e.g., you are a } \\
\text { facilitator, not a walking book of answers) and what is expected of everyone in } \\
\text { terms of participation and general respectfulness." (428, 2013, Female) }\end{array}$ \\
\hline
\end{tabular}


they set this environment by "bringing food" (34 excerpts) and "arranging the space" strategically (15 excerpts).

Peer leaders recommended bringing food because it creates an environment in which students feel cared for and therefore seem more willing to try out ideas and share explanations while solving complex problems. Peer leaders described how they arranged the space to improve the session by ensuring that each group is constructing its own knowledge about and solutions to the problems (see Table 4).

Group Expectations. In 41 excerpts (12\%), peer leaders focused on explaining expectations to their students (see Table 4), by "introducing the philosophy" of the PLTL program (22 excerpts), which focuses on the process of problem solving (instead of obtaining the answer). They also set "ground rules" for the group (19 excerpts), which focus on listening to others' ideas and promoting equal participation among the group.

\section{Finding 2 (Answering Research Question 2). Groups That Work: Peer Leaders Reported on Promoting Positive Collaborative Group Functioning and Full Participation by Knowing Their Students, Monitoring Group Interaction Unobtrusively, and Using Strategies to Ensure Participation in Discussion.}

The excerpts in the Group Dynamics theme were coded into three categories with almost equal weighting (see Figure 3): Group Functioning (39\%), Balancing Personalities (31\%), and Promoting Equal Participation (30\%). This almost equal balance of categories suggests that these ideas are closely

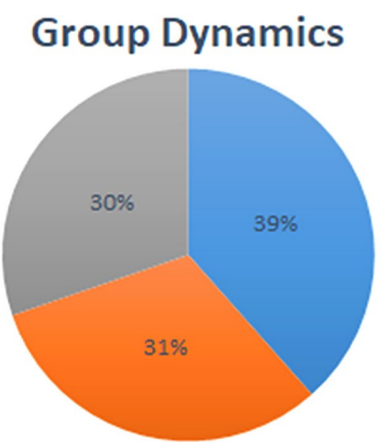

Group Functioning Balancing Personalities $\square$ Promoting Equal Participation

FIGURE 3. Percent of excerpts in categories within the Group Dynamics theme.

interrelated when managing group dynamics. Table 5 contains representative quotes for this theme. All categories and subcategories, their definitions, and example excerpts for the Group Dynamics theme are listed in Supplemental Table S2. In this theme, there was one subcategory with only one or two excerpts, and it is not discussed in the Results. This subcategory is still included in the coding guide (see the Supplemental Material), and the excerpts were counted toward the total number.

Group Functioning. To ensure group functioning (75 excerpts, $39 \%$ ), peer leaders described how they "grouped people strategically" (36 excerpts), kept "actively monitoring" the groups

TABLE 5. Representative quotes for the Group Dynamics theme

\begin{tabular}{|c|c|c|}
\hline Category & Representative subcategory & Corresponding representative quote \\
\hline \multirow[t]{2}{*}{ Group Functioning } & Actively monitor & $\begin{array}{l}\text { "Another tip to try during small groups or pairs is to walk around the } \\
\text { room and observe each group up close. This can allow students to ask } \\
\text { questions that they might not ask in front of the whole group, and it's } \\
\text { a way to get a feel for which students work faster and slower." (498, } \\
\text { 2015, Male) }\end{array}$ \\
\hline & Remind about philosophy & $\begin{array}{l}\text { "One the biggest struggles that I had with my PLTL was the 'bored' } \\
\text { student. These are students who are very familiar with the material. } \\
\text { They might seem annoyed that other students are not able to } \\
\text { understand the question and start working on the next problem on } \\
\text { their own. As a peer leader, don't be afraid to tell them to refrain } \\
\text { from moving onto the next problem! Remind them of the PLTL } \\
\text { philosophy and how this is supposed to be a group effort." (492, } \\
\text { 2015, Female) }\end{array}$ \\
\hline \multirow[t]{2}{*}{ Balancing Personalities } & Rein in dominant students & $\begin{array}{l}\text { "Scribe is a great tool if you find that your dominant student seems to be } \\
\text { running away with the conversation. Scribe puts the dominant } \\
\text { student at the board and gives other students a chance to talk while } \\
\text { keeping the dominant student engaged." (494, 2015, Female) }\end{array}$ \\
\hline & Encourage quiet students & $\begin{array}{l}\text { "You can ask the quiet students to write their work on the board once } \\
\text { their group has finished. This will let you know whether the student } \\
\text { simply sat and wrote down what the dominant student said or if they } \\
\text { truly understand the material." (496, 2015, Male) }\end{array}$ \\
\hline \multirow[t]{2}{*}{ Promoting Equal Participation } & Call on students & $\begin{array}{l}\text { "Additionally, making an active effort to ensure everyone speaks at least } \\
\text { once throughout the session can really help to foster a more balanced } \\
\text { discussion." (491, 2015, Female) }\end{array}$ \\
\hline & Use turn-taking & $\begin{array}{l}\text { "Using Round Robin after a question allows every student to participate } \\
\text { and contribute a bit to the problem-it is truly a group work to solve } \\
\text { the strategy! This way, both quiet and dominant students can equally } \\
\text { contribute to the question and create a leveled learning environ- } \\
\text { ment." (492, 2015, Female) }\end{array}$ \\
\hline
\end{tabular}


during the session (21 excerpts), and "reminded students of the program philosophy” (18 excerpts).

From the peer-leaders' quotes (see Table 5), actively monitoring groups means 1) paying attention to how students are working together, their strengths and weaknesses, their pace, how they relate to one another; and 2) encouraging studentstudent discussion without interfering with the group discussion. Knowing the students allowed peer leaders to be more strategic when grouping students for a problem to either complement one another or control the pace of work. Knowing how the students worked in groups allowed peer leaders to be flexible in adapting the collaborative-learning strategies to improve student-student discussion.

Balancing Personalities. To handle different personalities in the groups (61 excerpts, 31\%), peer leaders described how they "reined in the dominant students" (34 excerpts) and "encouraged the quiet students" (23 excerpts). There was a subcategory in Balancing Personalities with only a few excerpts, and it is not described in the Results, but it is included in the coding guide. Table 5 contains quotes for approaches to manage dominant students and encourage quiet students. Peer leaders emphasized two key underlying principles in supporting quiet students: ensure that these students have a voice and can express their understanding of the material, giving the other students an opportunity to get to know and hear these quiet students.

Promoting Equal Participation. Peer leaders ensured equal participation from students (59 excerpts, 30\%) by directly "calling on students" (26 excerpts), having students "take turns when speaking" (23 excerpts), and "getting students to talk in front of others" (10 excerpts). Table 5 contains representative quotes on encouraging quiet students and on having students take turns when speaking.

\section{Finding 3 (Answering Research Question 3). Facilitating Learning: Peer Leaders Reported That They Keep Students Moving Forward Together and Encouraging Collaborative Knowledge Building without Giving Answers by Pacing Sessions, by Using Questioning Strategies, and by Changing-Up the Session Structure.}

In PLTL, peer leaders are instructed not to provide solutions, so keeping students moving forward in the problem-solving process without showing them how to solve the problem requires explicit approaches. Figure 4 shows the percent of excerpts in the five categories for the Facilitation theme, and the top two facilitation strategies are pacing sessions and questioning strategically.

Peer leaders provided strategies to control pacing (37 excerpts, 36\%) and purposely questioning or redirecting questions to students (31 excerpts, 30\%). Peer leaders motivated students to stay on top of material (17 excerpts, 16\%) so that the sessions would remain productive. In addition, peer leaders structured sessions (14 excerpts, 13\%) to ensure that the group moved forward together. Finally, peer leaders promoted group independence ( 5 excerpts, $5 \%$ ) by having students learn to rely on one another to collaboratively solve the problems. Table 6 contains representative quotes for this theme. All categories and subcategories, their definitions and example excerpts for the

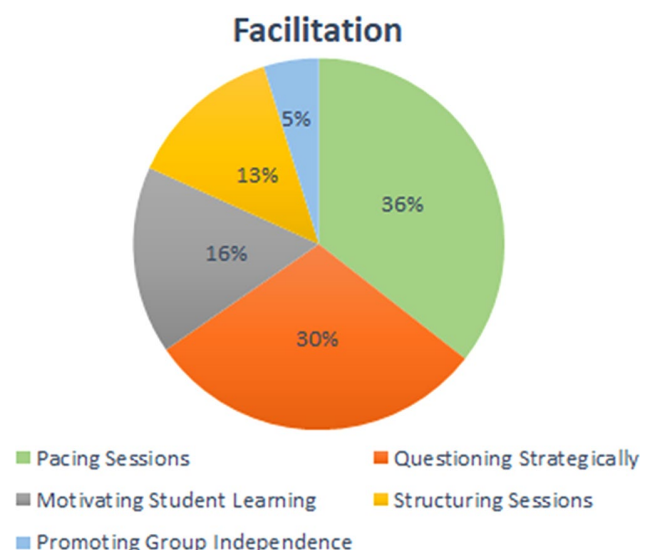

FIGURE 4. Percent of excerpts in categories within the Facilitation theme.

Facilitation theme are listed in Supplemental Table S3. In the categories Pacing Sessions, Structuring Sessions, and Promoting Group Independence, some subcategories had only a few excerpts and are not described in the Results, but these subcategories are included in the coding guide.

Pacing Sessions. To ensure that students collaboratively solved the problem rather than working independently, peer leaders controlled group pacing (37 excerpts, 36\%). They modified the collaborative-learning strategies to ensure that students were "moving together" (22 excerpts); see Table 6 for a representative quote.

Questioning Strategically. To encourage more studentstudent discussion and collaborative knowledge building, peer leaders used three questioning strategies (redirection, asking open-ended guiding questions, and asking for an explanation; 31 excerpts, 30\%). To nudge the group forward, "redirection of questions" back to students (8 excerpts) and, if redirection failed, "asking open-ended guiding questions" (14 excerpts) were recommended (see Table 6). When students were heading in the right direction but could not seem to find the next step or seemed confused about the work shown so far, peer leaders suggested asking students to "explain their thought process" ( 9 excerpts); see Table 6 for a representative quote. This can look like redirection, but has the objective of encouraging verbalization of conceptual or procedural explanations to establish deeper connection between concepts-an act students normally do not perform without prompting (Knight et al., 2015; Repice et al., 2016).

Motivating Student Learning. To ensure productive discussion, peer leaders recommended motivating student learning (17 excerpts, 16\%) so that students will want to contribute. In addition, "promoting preparation" (7 excerpts) was necessary as the semester progressed. Noting that multiple types of incentives are helpful, especially during the "midsemester slump"; peer leaders "provided incentives" (10 excerpts) about student learning by sharing their own academic experiences (see Table 6). 
TABLE 6. Representative quotes for the Facilitation theme

\begin{tabular}{|c|c|c|}
\hline Category & Representative subcategory & Corresponding representative quote \\
\hline Pacing Sessions & Move together & $\begin{array}{l}\text { "For my group, [round robin] just meant that they could contribute one } \\
\text { small factor to the problem, and then they would have a whole } \\
\text { rotation to solve the problem alone on their own packets. They } \\
\text { weren't learning anything new this way, they were just moving } \\
\text { through the problem. To keep this from happening, I decided to have } \\
\text { each contributor write his or her step on the board and then toss the } \\
\text { marker to someone else, popcorn style. This forced everyone to keep } \\
\text { their heads up and engaged ... [and] to see how the solution to the } \\
\text { problem was growing up on the board." (472, 2014, Male) }\end{array}$ \\
\hline Questioning Strategically & Guide via questions & $\begin{array}{l}\text { "Use open-ended questions. Get your students thinking about the } \\
\text { concepts from the notes that they've taken. I remember being } \\
\text { amazed at how quickly the students could make sense of a tough } \\
\text { problem after I presented an open-ended question to help them } \\
\text { target their attention to a particular concept." (434, 2013, Male) }\end{array}$ \\
\hline Motivating Student Learning & Provide incentives & $\begin{array}{l}\text { "It might also be helpful to comment on your own experiences with } \\
\text { either falling behind in a class or not attending lectures on time, } \\
\text { since that way they will feel like they can still catch up to the class } \\
\text { and succeed; some students fall so far behind that they don't even } \\
\text { think it is possible to do well in the class anymore." (438, 2013, } \\
\text { Female) }\end{array}$ \\
\hline Structuring Sessions & Add variety & $\begin{array}{l}\text { "My sessions started to get a little repetitive and tedious during the } \\
\text { middle of the semester so I tried to spice it up through a few different } \\
\text { methods. Although it may seem small, changing up who your } \\
\text { students work with in small groups can provide a lot of new energy } \\
\text { to the group. Also, you can modify a problem solving strategy to do } \\
\text { something new, such as using a talking stick for round robin or } \\
\text { switching scribes throughout a problem." (471, 2014, Female) }\end{array}$ \\
\hline
\end{tabular}

Structuring Sessions. Peer leaders explicitly described adapting session structure (14 excerpts, 13\%) to keep up the group's energy. This is mostly achieved by "adding variety" (12 excerpts) to their sessions for better flow (see Table 6).

Promoting Group Independence. To promote group independence (5 excerpts, $5 \%$ ), peer leaders emphasized the importance of first allowing students to "struggle" (4 excerpts) through problems on their own (see Table 6).

\section{DISCUSSION}

Through our analysis, we examined the practiced advice and strategies that chemistry peer leaders self-reported they used to facilitate robust student-student discourse that encourages collaborative knowledge and skill building during complex problem solving. Specifically, we explored how, to improve student-student discussion, peer leaders reported that they 1) created conducive learning environments, 2) adapted their tactics and the collaborative-learning strategies to manage group dynamics, and 3) refined their own approaches to facilitate sessions, all of which are important skills for peer instructors who work with students taking STEM courses, especially introductory courses.

\section{Creating a Conducive Community-Oriented Environment for Collaborative Learning}

Peer leaders set up an environment conducive to peer collaborative learning by focusing predominantly on 1) peer-leader attitude, especially toward encouraging students to adopt a growth mindset in chemistry and not to expect to know solutions to problems immediately; and 2) fostering a social and intellectual environment that is welcoming and community oriented, which allows for risk taking by group members. For example, having a constructive attitude toward open discussion and multiple ideas encourages students to feel comfortable in discussing possible solutions to the problems and in making mistakes during those discussions (Boud, 2001; Sawyer et al., 2013b). Other peer-leader studies (Tien et al., 2002; Gafney and Varma-Nelson, 2008) also found that peer leaders stressed the importance of a community-oriented environment. 
Another, but important, point in setting the environment involved explaining (and upholding) the responsibilities of group members in the sessions, which includes establishing ground rules and discussing (and cultivating) the PLTL philosophy. The peer leaders emphasized that member expectations should be discussed at the first session and need to be reiterated at crucial points throughout the semester (e.g., after the first exam, midsemester, and near the final).

\section{Promoting Collaborative Group Dynamics Including Full Participation}

In discussing group dynamics, the peer leaders advised that the following three components have equal importance 1) working on creating a functional group, 2) balancing different personalities, and 3) promoting equal participation among all students in the group. Key points comprise 1) actively monitoring (without interfering) the groups by paying attention to how students are working together and using this information to create robust student-student discussion; 2) using and modifying collaborative-learning strategies (e.g., round robin and scribe) to support all personality types within the group; and 3) ensuring that students equally participate by, for example, providing different types of opportunities for students to report out to the larger group. These three components were essential in promoting robust student-student discussion, including taking risks, during problem solving. In collaborative groups, as seen in Repice et al. (2016, p. 566), students develop social and communicative skills to use in these academic settings: "Students took on regulative roles within the social environment to ask for clarification, check on their understanding, attempt to explain complex ideas, move toward consensus, and mediate disagreements." These approaches require that peer leaders get to know their students and personalities and then select a variety of strategies that work with their students to ensure equal participation and robust discussion, which involves the peer leader staying attentive and modifying the collaborative-learning strategies appropriately.

\section{Facilitating Learning to Keep Students Moving Forward Together and Encouraging Collaborative Knowledge Building without Providing Answers}

To keep students working together without giving answers or leading students through the problem, peer leaders put the PLTL philosophy into practice. The primary approaches peer leaders used were 1) controlling the pace of the groups by modifying the collaborative-learning strategies; and 2) using questioning, redirection, or student-student explanation throughout the problem-solving process in addition to when the group is stuck during problem solving. As seen in Repice et al. (2016), while solving complex problems, the emphasis in PLTL via the collaborative-learning strategies on turn taking and moving together results in students presenting their different approaches to solving the problems, receiving feedback on those approaches and explanations, and practicing joint decision making, all of which culminates in their building knowledge collaboratively. Knight et al. (2015) found students engaging in more robust and conceptual discussions when the peer leaders in their LA program used questions to encourage deep explanations instead of explaining the concepts/solutions themselves. These studies show that collaborative group settings provide multiple oppor- tunities for students to collectively learn and practice communicating in the language of science. Through using these strategies, peer leaders are supporting their students in becoming independent learners by allowing students to struggle during the problem-solving process while being supported and thus becoming more confident of their problem-solving abilities, which peer leaders discussed as important in the Tien et al. (2002) study.

\section{Developing a CoP for Peer Leaders}

Our training program creates a multilayered set of communities of practice for peer leaders that encourages emerging peer leaders to build upon the knowledge and experience of prior peer leaders; incorporate these strategies and insights into their sessions; and then refine, add to, and pass on to the next cohort what they have learned from their own peer-leading experiences. The peer leaders in these CoPs engaged in structured activities that promoted the sharing and modifying of these practices and encouraged support for one another as they developed their individual skills. Having these CoPs, in addition to the two training courses, broadly expanded our peer leaders' ability to create groups to foster robust student-student discussion and collaborative knowledge building during problem solving. In several studies (Tien et al., 2002; Gafney and Varma-Nelson, 2008; Otero et al., 2010), peer leaders expressed that having a supportive community of their peers was important to their success as peer leaders. Hence, instructors training peer leaders of collaborative groups may think about formalizing the use of CoPs and thereby making visible to emerging peer leaders the available supportive community.

We also discovered evidence of peer leaders communicating across cohorts to provide acknowledgment of the complex task of facilitating peer-learning sessions for collaborative problem solving. For example, peer leaders wrote these encouraging words:

"While it may seem to be a daunting task to remember all the different topics of general chemistry, reviewing these topics in the PAM class will help it all come right back to you...Your first session may be the most nerve-racking, but just keep in mind that with each subsequent session, you will feel more and more comfortable as a mentor." (456, 2014, Male)

"Build up a solid routine of consistent and effective usage of the strategies, and that will set a strong tone for the rest of the semester. If you haven't quite gotten there yet, don't worry! Always keep in mind that getting your students to collaborate isn't an impossibility. All it takes is just a little bit of creativity, adaptability, and optimism!" (445, 2013, Female)

Thus, we see that a key element in learning - for peer leaders and their students - seems to be a supportive near-peer community. Through each iteration of the SAM book, we saw how our multilayered CoP model worked to transmit practiced advice and insights about peer leading from one generation of peer leaders to the next, as well as emotional support. These books allowed emerging peer leaders to learn from and add to the database of advice and strategies built by their predecessors. 
This study gives evidence of what emerging peer leaders deemed to be important advice for facilitating successful collaborative peer learning via essays in an annual book written in their first peer-leading semesters, in combination with written reflections of their sessions, discussions with other peer leaders (emerging and experienced), discussions of learning theory and education research, and feedback from observations of their sessions by other peer leaders and instructors. These annual books provide a space for cognitive apprenticeship, by bridging the ZPD, and creating a near-peer CoP (Collins et al., 1988). This advice has been modified and added to throughout several generations of peer leaders via the SAM books, and therefore could be considered when training peer leaders of collaborative peer-instruction programs. In fact, through private communication with the corresponding author (R.F.F.), over the years, dozens of institutions have commented that they use our SAM books in training their PLTL peer leaders.

We recognize that there is a limitation to the use of our chosen theoretical frameworks in this study, because we present what peer leaders themselves deemed was important to pass on to new peer leaders in the form of advice books, and that the advice and insights are a self-report of what these peer leaders observed, practiced, and used in their sessions. However, these insights and advice were corroborated by other peer leaders in the larger CoP via discussions held during the SAM and PAM courses, by the discussion posts and responses in the SAM course, and by the commonality of the advice and insights given in these books over 13 years. Through our research results, we found that the majority of the written advice was similar yet modified and added to throughout the years of books, and that the SAM books reflect the key strategies that the peer leaders chose to pass on to their peers who will facilitate students in small groups in large, introductory STEM courses.

\section{IMPLICATIONS}

The practiced strategies and insights shared by the peer leaders are useful for collaborative group sessions throughout STEM academic departments. We recommend that trainers and practitioners find ways to communicate these strategies within their own groups, while reflecting on how to modify these strategies to best fit their own situations. The advice and insights shared by the peer leaders through these annual books provide a flexible tool kit of strategies that can be used, modified, and added to.

The use of CoPs promotes creation and maintenance of community and a supportive environment for our peer leaders' learning. There is something powerful and connective about emerging peer leaders learning from a recent cohort of peer leaders. Emerging peer leaders may benefit from hearing the experiences of near peers who recently went through the process of becoming a peer leader during their own learning about facilitation and effective leadership of peer groups. The peer leaders who write the SAM book are reflecting on their experiences and intentionally offering advice, support, and information that they feel will be helpful to future emerging peer leaders. New peer leaders may be more willing to take ideas and advice from past peer leaders whom they feel really understand this complex role.

We believe that to train collaborative peer leaders, instructors should find ways to build in reflective practices and opportunities for peer leaders to share knowledge and experiences with one another, across cohorts, as a way to build community. Through this larger CoP information is passed down, changed, added to, and transformed to reflect the diverse experiences of the peer leaders. In this CoP, the members recognize that there are multiple ways to solve issues that arise, and it is important that this wisdom gets transformed and then transmitted from generation to generation.

\section{ACKNOWLEDGMENTS}

We thank all the peer leaders throughout the years who have contributed much to our Peer-Led Team Learning (PLTL) program and to the improved learning of our students in General Chemistry. We also thank the editor and the anonymous reviewers whose comments and suggestions have added much to this paper.

\section{REFERENCES}

Andriessen, J. (2006). Arguing to learn. In Sawyer, R. K. (Ed.), The Cambridge handbook of the learning sciences (pp. 443-459). New York: Cambridge University Press

Arendale, D. R. (2015). Postsecondary peer cooperative learning programs: Annotated bibliography. Retrieved January 2, 2020, from https://conservancy umn.edu/handle/11299/190796

Bandura, A. (1977). Self-efficacy: Toward a unifying theory of behavioral change. Psychological Review, 84(2), 191-215.

Batz, Z., Olsen, B. J., Dumont, J., Dastoor, F., \& Smith, M. K. (2015). Helping struggling students in introductory biology: A peer-tutoring approach that improves performance, perception, and retention. CBE-Life Sciences Education, 14(2), ar16.

Becker, N., Rasmussen, C., Sweeney, G., Wawro, M., Towns, M., \& Cole, R. (2013). Reasoning using particulate nature of matter: An example of a sociochemical norm in a university-level physical chemistry class. Chemistry Education Research and Practice, 14(1), 81-94.

Bodner, G. M., Klobuchar, M., \& Geelan, D. (2001). The many forms of constructivism. Chemical Educator, 78, 1107

Bogdan, R., \& Biklen, S. (2003). Qualitative research for education. An introduction to theories and methods. New York: Pearson.

Boud, D. (2001). Introduction: Making the move to peer learning. In Boud, D., Cohen, R., \& Sampson, J. (Eds.), Peer learning in higher education (pp. 1-17). Sterling, VA: Kogan Page.

Brown, J. S., Collins, A., \& Duguid, P. (1989). Situated cognition and the culture of learning. Educational Researcher, 18(1), 32-42.

Brown, P., Sawyer, K. R., Frey, R., Luesse, S., \& Gealy, D. (2010). What are they talking about? Findings from an analysis of the discourse in peer-led team learning in general chemistry. In Proceedings of the 9th international conference of the learning sciences (Vol. 1, pp. 773-777). Chicago, IL: International Society of the Learning Sciences.

Carlsen, W. S. (1993). Teacher knowledge and discourse control: Quantitative evidence from novice biology teachers' classrooms. Journal of Research in Science Teaching, 30(5), 471-481.

Carlson, K., Turvold Celotta, D., Curran, E., Marcus, M., \& Loe, M. (2016) Assessing the impact of a multi-disciplinary peer-led-team learning program on undergraduate STEM education. Journal of University Teaching $\&$ Learning Practice, 13(1), ar5

Chan, J. Y. K., \& Bauer, C. F. (2015). Effect of peer-led team learning (PLTL) on student achievement, attitude, and self-concept in college general chemistry in randomized and quasi experimental designs. Journal of Research in Science Teaching, 52(3), 319-346.

Collins, A., Brown, J. S., \& Newman, S. E. (1988). Cognitive apprenticeship: Teaching the craft of reading, writing and mathematics. Thinking: The Journal of Philosophy for Children, 8(1), 2-10.

Dennen, V. P., \& Burner, K. J. (2008). The cognitive apprenticeship model in educational practice. Handbook of Research on Educational Communications and Technology, 3, 425-439.

Denzin, N. K., \& Lincoln, Y. S. (2003). Collecting and interpreting qualitative materials. Thousand Oaks, CA: Sage. 
Drane, D., Smith, H. D., Light, G., Pinto, L., \& Swarat, S. (2005). The gateway science workshop program: Enhancing student performance and retention in the sciences through peer-facilitated discussion. Journal of Science Education and Technology, 14(3), 337-352.

Dunlosky, J., Rawson, K. A., Marsh, E. J., Nathan, M. J., \& Willingham, D. T. (2013). Improving students' learning with effective learning techniques: Promising directions from cognitive and educational psychology. Psychological Science in the Public Interest, 14(1), 4-58.

Eberlein, T., Kampmeier, J., Minderhout, V., Moog, R. S., Platt, T., Varma-Nelson, P., \& White, H. B. (2008). Articles pedagogies of engagement in science: A comparison of PBL, POGIL, and PLTL. Biochemistry Molecular Biology Education, 36, 262-273

Eren-Sisman, E. N., Cigdemoglu, C., \& Geban, O. (2018). The effect of peerled team learning on undergraduate engineering students' conceptual understanding, state anxiety, and social anxiety. Chemistry Education Research and Practice, 19, 694-710.

Frey, R. F., Fink, A., Cahill, M. J., McDaniel, M. A., \& Solomon, E. D. (2018) Peer-led team learning in general chemistry I: Interactions with identity, academic preparation, and a course-based intervention. Journal of Chemical Education, 95(12), 2103-2113.

Gafney, L., \& Varma-Nelson, P. (2008). Peer-led team learning: Evaluation, dissemination, and institutionalization of a college level initiative (Vol. 16). New York: Springer Science \& Business Media.

Glaser, B. G., \& Strauss, A. (1967). The discovery of grounded theory: Strategies for qualitative research. Piscataway, $\mathrm{NJ}$ : Transaction Publishers.

Glover, R., Hammond, N. B., Smith, J., \& Guerra, D. (2018). Assessing peer leader skill acquisition and group dynamics in a first-year calculus course. International Journal for the Scholarship of Teaching and Learning, 12(1), ar10

Gosser, D., Roth, V., Gafney, L., Kampmeier, J., Strozak, V., Varma-Nelson, P., .. \& Weiner, M. (1996). Workshop chemistry: Overcoming the barriers to student success. Chemical Educator, 1, 1-17.

Gosser, D. K., \& Roth, V. (1998). The Workshop Chemistry Project: Peer-led team learning. Journal of Chemical Education, 75(2), 185-187.

Hanrahan, M. U. (2005). Highlighting hybridity: A critical discourse analysis of teacher talk in science classrooms. Science Education, 90(1), 8-43.

Hockings, S. C., DeAngelis, K. J., \& Frey, R. F. (2008). Peer-led team learning in general chemistry: Implementation and evaluation. Journal of Chemical Education, 85(7), 990-996.

Johnson, E. C., Robbins, B. A., \& Loui, M. C. (2015). What do students experience as peer leaders of learning teams? Advances in Engineering Education, 4(4), 1-22.

Knight, J. K., Wise, S. B., Rentsch, J., \& Furtak, E. M. (2015). Cues matter: Learning assistants influence introductory biology student interactions during clicker-question discussions. CBE-Life Sciences Education, 14(4), $\operatorname{ar41.~}$

Krajcik, J. S., \& Blumenfeld, P. C. (2006). Project-based learning, In Sawyer, R. $\mathrm{K}$. (Ed.), The Cambridge handbook of the learning sciences (pp. 317334). New York: Cambridge University Press.

Krippendorff, K. (2004). Reliability in content analysis. Human Communication Research, 30(3), 411-433.

Kudish, P., Shores, R., McClung, A., Smulyan, L., Vallen, E. A., \& Siwicki, K. K. (2016). Active learning outside the classroom: Implementation and outcomes of peer-led team-learning workshops in introductory biology. CBE-Life Sciences Education, 15(3), ar31.

Kulatunga, U., Moog, R. S., \& Lewis, J. E. (2013). Argumentation and participation patterns in general chemistry peer-led sessions. Journal of Research in Science Teaching, 50, 1207-1231.

Lave, J., \& Wenger, E. (1991). Situated learning: Legitimate peripheral learning. In Learning in doing: Social, cognitive and computational perspectives (pp. 89-106). Cambridge, UK: Cambridge University Press.

Learning Assistant Alliance. (2011). Home page. Retrieved January 2, 2020, from https://learningassistantalliance.org

Lemke, J. L. (1990). Talking science: Language, learning, and values. Norwood, NJ: Ablex Publishing

Lewis, S. E. (2011). Retention and reform: An evaluation of peer-led team learning. Journal of Chemical Education, 88(6), 703-707.

Lombard, M., Snyder-Duch, J., \& Bracken, C. C. (2005). Practical resources for assessing and reporting intercoder reliability in content analysis research projects. Retrieved January 2, 2020, from www.researchgate .net/profile/Cheryl_Bracken/publication/242785900_Practical_Resources _for_Assessing_and_Reporting_Intercoder_Reliability_in_Content _Analysis_Research_Projects/links/0deec52e14791a0d6f000000.pdf

Micari, M., Streitwieser, B., \& Light, G. (2006). Undergraduates leading undergraduates: Peer facilitation in a science workshop program. Innovative Higher Education, 30(4), 269-288.

Otero, V., Pollock, S., \& Finkelstein, N. (2010). A physics department's role in preparing physics teachers: The Colorado Learning Assistant Model. American Journal of Physics, 78(11), 1218-1224.

Patton, M. Q. (2002). Qualitative research and evaluation methods (3rd ed.) Thousand Oaks, CA: Sage.

Peteroy-Kelley, M. A. (2007). A discussion group program enhances the conceptual reasoning skills of students enrolled in a large lecture-format introductory biology course. Journal of Microbiology \& Biology Education, 8(1), 13-21.

Potter, W. J., \& Levine-Donnerstein, D. (1999). Rethinking validity and reliability in content analysis. Journal of Applied Communication Research, 27(3), 258-284

Preszler, R. W. (2009). Replacing lecture with peer-led workshops improves student learning. CBE-Life Science Education, 8, 182-192.

Repice, M. D., Keith Sawyer, R., Hogrebe, M. C., Brown, P. L., Luesse, S. B., Gealy, D. J., \& Frey, R. F. (2016). Talking through the problems: A study of discourse in peer-led small groups. Chemistry Education Research and Practice, 17(3), 555-568.

Sawyer, K., Frey, R., \& Brown, P. (2013a). Peer-led team learning in general chemistry. In Productive multivocality in the analysis of group interactions (pp. 183-189). Boston, MA: Springer.

Sawyer, K., Frey, R., \& Brown, P. (2013b). Knowledge building discourse in peer-led team learning (PLTL) groups in first-year general chemistry. In Productive multivocality in the analysis of group interactions (pp. 191204). Boston, MA: Springer.

Sawyer, R. K. (2005). Introduction. In Sawyer, R. K. (Ed.), The Cambridge handbook of the learning sciences (pp. 1-16). New York: Cambridge University Press.

Sellami, N., Shaked, S., Laski, F. A., Eagan, K. M., \& Sanders, E. R. (2017) Implementation of a learning assistant program improves student performance on higher-order assessments. CBE-Life Sciences Education, 16(4), ar62.

Snyder, J. J., \& Wiles, J. R. (2015). Peer-led team learning in introductory biology: Effects on critical thinking skills. PLOS ONE, 10, 1-18.

Talbot, R. M., Hartley, L. M., Marzetta, K., \& Wee, B. S. (2015). Transforming undergraduate science education with learning assistants: Student satisfaction in large-enrollment courses. Journal of College Science Teaching, 44(5), 24-30.

Tien, L. T., Roth, V., \& Kampmeier, J. A. (2002). Implementation of a peer-led team learning instructional approach in an undergraduate organic chemistry course. Journal of Research in Science Teaching, 39(7), 606-632.

Tien, L. T., Roth, V., \& Kampmeier, J. A. (2004). A course to prepare peer leaders to implement a student-assisted learning method. Journal of Chemical Education, 81(9), 1313-1321.

Van Dusen, B., Langdon, L., \& Otero, V. (2015, July). Learning assistant supported student outcomes (LASSO) study initial findings. In The Physics Education Research Conference Proceedings (pp. 1-4). College Park, MD: American Association of Physics Teachers (AAPT) and the Physics Education Research Topical Group (PERTG).

Vygotsky, L. S. (1980). Mind in society: The development of higher psychological processes. Cambridge, MA: Harvard University Press.

Wenger, E. (1997). Communities of practice: Learning, meaning and identity. Cambridge, UK: Cambridge University Press.

Wilson, S. B., \& Varma-Nelson, P. (2016). Small groups, significant impact: A review of peer-led team learning research with implications for STEM education researchers and faculty. Journal of Chemical Education, 93(10), 1686-1702.

Yin, R. (2010). Qualitative research from start to finish. New York: Guilford Press.

Young, K. K., \& Talanquer, V. (2013). Effect of different types of small-group activities on students' conversations. Journal of Chemical Education, 90, 1123-1129. 